\title{
Clinical assessment of cervical movement sense in those with neck pain compared to asymptomatic individuals.
}

\author{
Markus J. Ernst ${ }^{1}$ \\ Lauren Williams ${ }^{2}$ \\ Isabelle M. Werner ${ }^{3}$ \\ Rebecca J. Crawford 4 \\ Julia Treleaven ${ }^{2}$
}

${ }^{1}$ Institute of Physiotherapy, Zurich University of Applied Sciences, Technikumstrasse 71, 8401

Winterthur, Switzerland. markus.ernst@zhaw.ch),Phone: +415893464 48

(corresponding author

${ }^{2}$ Cervical spine research Unit, University of Queensland, Brisbane, Australia, lauren.williams2@uqconnect.edu.au

${ }^{2}$ Cervical spine research Unit, University of Queensland, Brisbane, Australia j.treleaven@uq.edu.au

${ }^{3}$ Department of Physiotherapy, Kantonsspital Schaffhausen, Geissbergstrasse 81, 8208

Schaffhausen, Switzerland. isabellewerner@hotmail.com

${ }^{4}$ Body Urbanism BV, Nieuwe Binnenweg 136, 3015 BE, Rotterdam, Netherlands.

crawford.ri.ac@gmail.com

\section{Acknowledgements}

The authors thank all raters and subjects for participating.

\section{Declaration of interest:}

None 
Ethical approval:

The ethical committees of the University of Queensland (H/246/PHYSIO/00/M) and the Canton of Zurich (Register No.: 2017-00311) approved the study.

Funding:

None 
2 Clinical assessment of cervical movement 3 sense in those with neck pain compared to asymptomatic individuals. 
Keywords:

8 Cervical spine, joint movement sense, idiopathic neck pain, whiplash, validity

9

10

11

12

13

14

15

16

17 


\section{Background}

Sensorimotor control dysfunction, such as impaired head and eye movement control and postural stability occurring concurrent with neck pain (NP), is thought to be due to altered cervical afferent input or impaired cervical proprioception. (Jull et al. , 2008, Kristjansson and Treleaven, 2009, Kulkarni et al. , 2001, Liu et al. , 2003, McLain, 1994, Richmond and Bakker, 1982). Negative long-term consequences of impaired proprioception can lead to further injury, recurrence, and chronicity (Kristjansson et al. , 2016, Roijezon et al. , 2015). Subjective symptoms associated with impaired cervical proprioception include dizziness and light-headedness, and are more common in patients after whiplash (WAD) (Treleaven, 2011, Woodhouse et al. , 2010b). Importantly, they are associated with poor prognosis and should be managed early (Treleaven, 2011). Thus, assessment and management of cervical proprioception is important in the management of NP.

Recent prospective studies revealed improvements in cervical movement sense (CMS) in subjects with NP receiving intervention to address motor control and stability (Kristjansson et al., 2016, Meisingset et al. , 2015, Sarig Bahat et al. , 2015b, Treleaven et al. , 2016). However, such impairments are often subtle and can remain undetected with conventional physical examination necessitating special tests to examine cervical proprioception (Oddsdottir and Kristjansson, 2012).

Assessment of CMS determines the ability to smoothly and precisely move the head/neck, usually to a given pattern (Michiels et al. , 2013). Various methods using equipment not readily clinically available can demonstrate CMS impairments in individuals with NP (Kristjansson and Oddsdottir, 2010, Oddsdottir and Kristjansson, 2012, Sarig Bahat et al. , 2015a, Woodhouse et al., 2010b).

A cost-effective and simple clinical alternative, where time and number of errors are recorded while tracing zigzag (ZZ) and figure of eight (F8) patterns with a head-affixed laser has been investigated in healthy asymptomatic and individuals with NP and shown to be reliable (Pereira et al. , 2013, Werner 
et al. , 2018). First indications of clinical feasibility were demonstrated but elaboration is needed (Werner et al., 2018).

Accordingly, the primary aim of this study was to examine differences in CMS between age- and gender-matched individuals with NP and asymptomatic controls to determine suitable cut-off measures for clinical interpretation. We also examined subgroup differences between patients with idiopathic neck pain (INP) and WAD.

\section{Methods}

Adult individuals with NP and age- and gender-matched asymptomatic controls were recruited for two separate university-based higher degree projects. The first, recruited individuals with $(n=18)$ and without NP ( $n=38)$ from the general public and community at XXXX. The second recruited additional individuals with NP, from the physiotherapy department of the XXXX hospital in XXXX ( $=20)$, matched by age and gender to the demographics of healthy subjects of the first cohort. Both projects received approval by their local ethical committees (XXXX and XXXX). All participants gave written informed consent prior to the measurements.

Participants were included in the NP group if they had traumatic or non-traumatic NP of more than three months duration and a minimum Neck Disability Index (NDI) score of 10\% (Vernon, 2008, Vernon and Mior, 1991). Control participants were included if they had no history of NP for which they sought treatment and a NDI of less than $4 \%$. Exclusion criteria included any current or history of medical conditions affecting nerves, muscles or joints, vestibular disorders or dysfunction, neurological or central nervous system conditions, disorders of eye movements or visual impairments, deafness, hearing aids or previous ear surgery, psychiatric disorders or head injury. 
All participants completed a demographic questionnaire recording gender, age, duration of the problem in months, current pain intensity (visual analogue scale; VAS) (Jensen et al. , 1986), and whether they were suffering from traumatic (WAD) or non-traumatic INP.

Pain and disability related to NP (MacDermid et al. , 2009, Vernon and Mior, 1991)), and dizziness and related symptoms (Dizziness Handicap Inventory short form (DHIsf) (Jacobson and Newman, 1990, Tesio et al. , 1999)) were also recorded.

Subjects completed the questionnaires and then performed CMS testing in random order and according to an established method (Werner et al., 2018). Briefly, subjects sat on a chair with backrest, one metre away from a board where the F8 or ZZ pattern was attached. Subjects wore a headband with an affixed laser pointer. With the subject sitting comfortably upright, each pattern was attached to the board so that the laser beam directed to the pattern centre. A video camera pattern (Figures 1 and 2). 


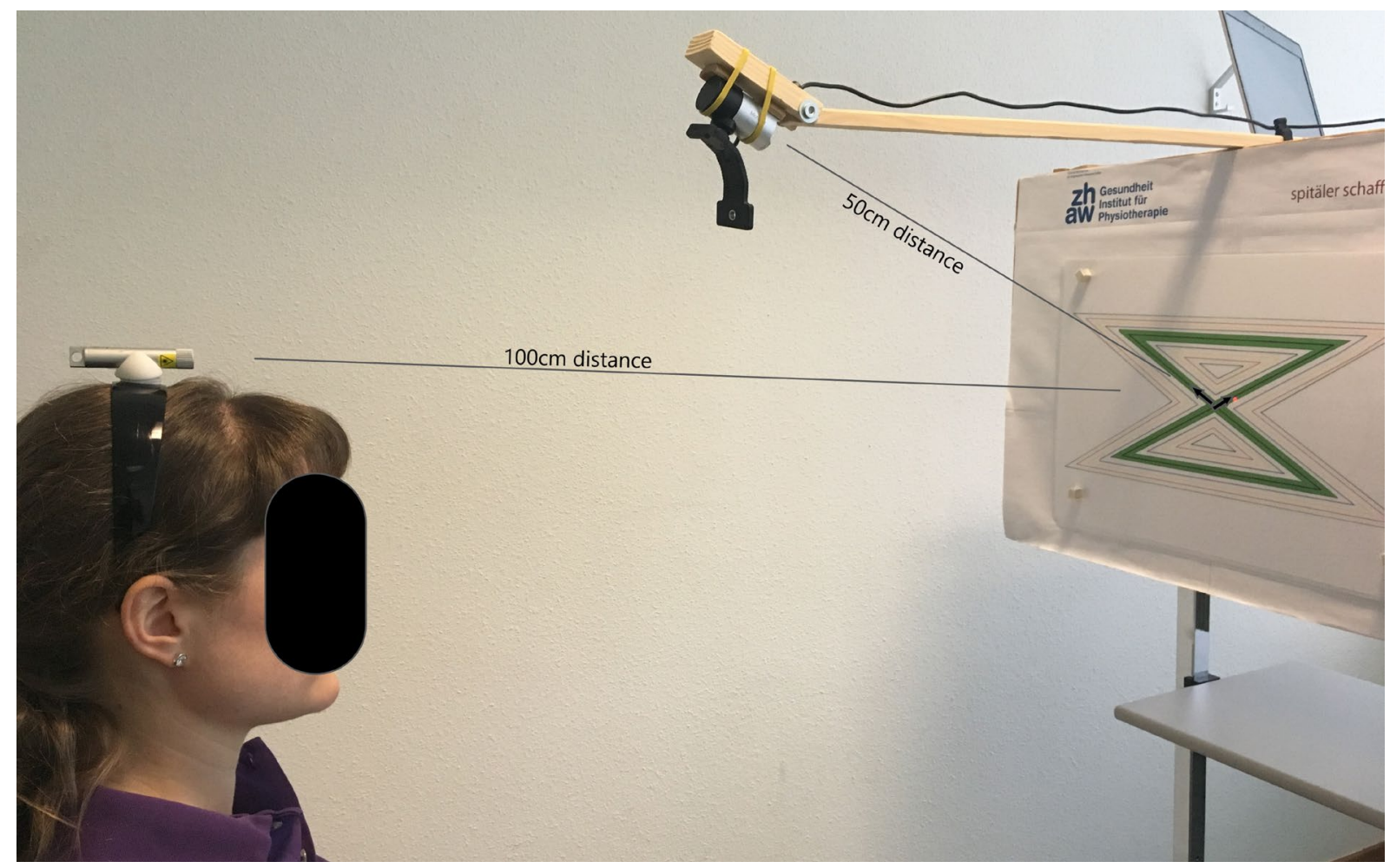

83 Figure 1: test-set up using the zigzag pattern. Arrows on the pattern indicate movement directions.

Figure 1a: For the zigzag pattern, an error was given whenever the laser beam left the inner green zone, which was $5 \mathrm{~mm}$ either side of the bold line.

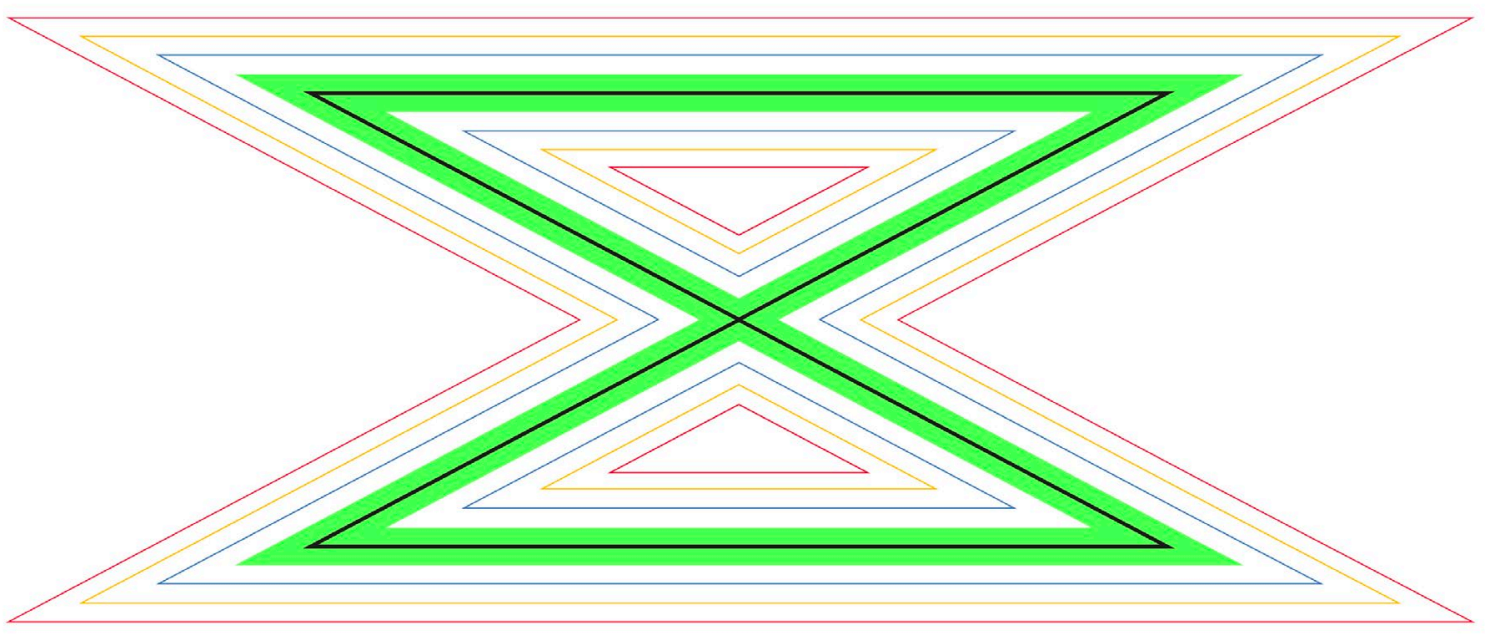




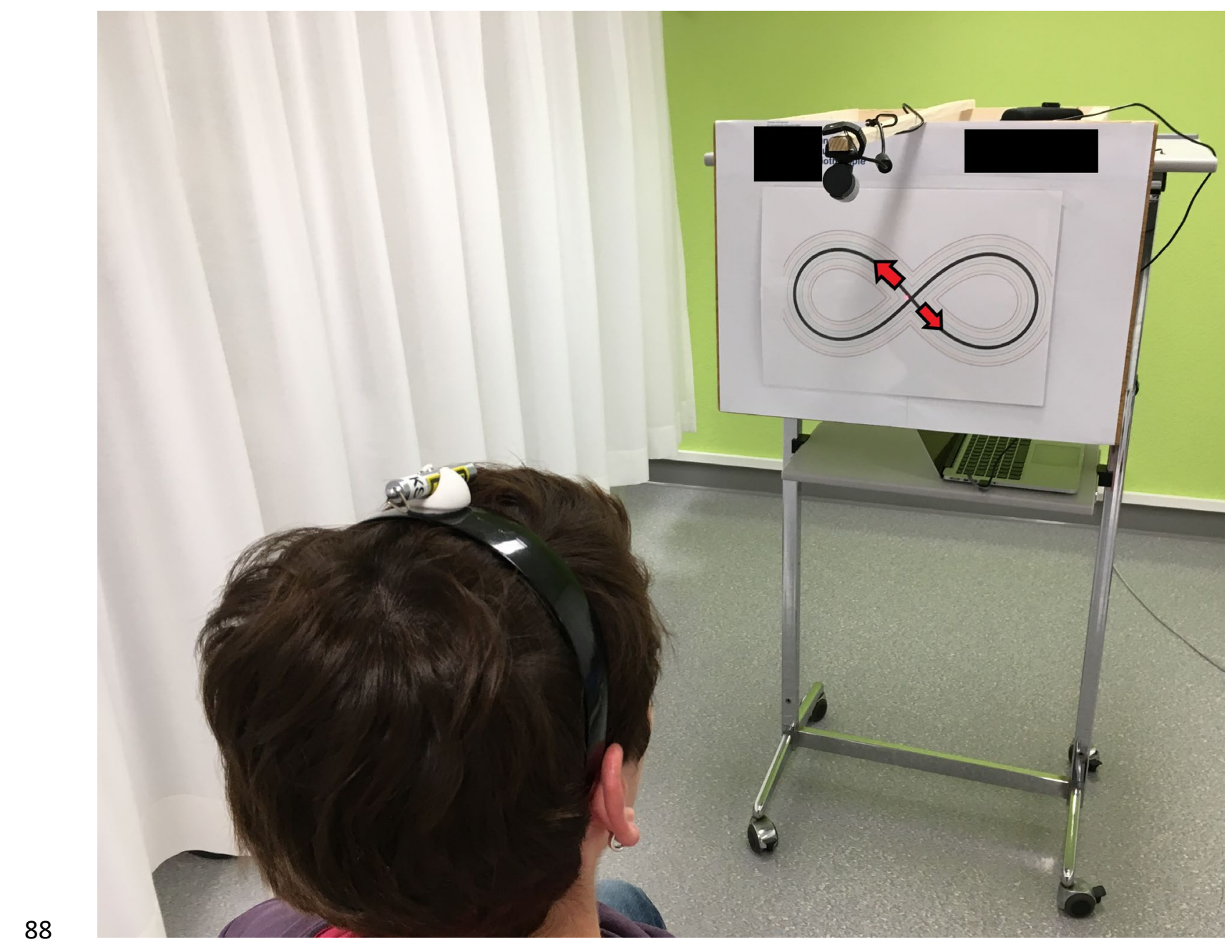

Figure 2: test-set up for Figure of 8: arrows on the pattern indicate movement directions

Patterns described previously (Werner et al., 2018) were printed on A3 paper where a $5 \mathrm{~mm}$ thick

black band (F8) and 10mm thick green band (ZZ) represented the central (main) pattern. Both

patterns had additional lines every $5 \mathrm{~mm}$ to both sides from the main line to distinguish further zones of deviation as per previous research but only the inner zone and thus number of errors was used in this analysis.

After one warm-up, subjects performed two repetitions for each pattern, one while starting to move first to the left and another starting first to the right. Subjects were asked to trace along the bold black line within the inner zone of each pattern as accurately as possible. If they moved outside of the zone, they were to return to the bold line as soon as possible. 
101

102

At each site, videos had been rated in real-time using the programme SMIPlayer

(https://www.smplayer.info). Two independent raters at the first site, who were also blind to the condition of each subject (NP or control) while one rater at the second site was blinded to first site's ratings and patient characteristics.

\section{Outcome parameters}

Two outcome variables for each pattern (ZZ and F8) and each direction were evaluated: 1 . Time needed to trace the pattern in seconds (time) and 2) real time number of errors, defined as the sum of deviations from the inner zone defined by the laser beam completely leaving the pattern inner zone when viewed on the video in real time. The inter-rater reliability has previously been shown to be perfect for time ratings and moderate to high for number of errors with standard errors of the measurements of 1 to 1.6 for $Z Z$ and close to 3 errors for F8 (Werner et al., 2018).

\section{Data processing and analysis}

Data from both university partners were recorded in a standardized way and combined for further analysis by using Cran-R version 3.4.1 including the packages "ROCR" and "epiR" (Peña and Slate, 2006, R-Development-Core-Team, 2008, Sing et al. , 2015, Stevenson, 2018).

\section{Preliminary statistical analysis revealed no significant differences in time or number of errors} between moving first to the left or the right for each pattern, thus the mean of both directions was computed and used for further analysis. Independent t-tests (cases vs. controls) were performed to detect differences between groups for age, NDI and DHIsf and time and number of errors for each pattern. Sensitivity and specificity for both patterns and outcome variables and for different cut-offs were computed using four seconds intervals in time and two errors intervals in number of errors (Akobeng, 2007, Streiner and Norman, 2008). Optimal cut-off points were derived and, by using the receiver operating curve $(\mathrm{ROC})$ method, the largest area under the curve for both, sensitivity (true positive) and 1- specificity (false positive), denoted the optimal cut-off (Akobeng, 2007). Positive 
$(L R+)$ and negative likelihood ratios (LR-) for each cut-off were calculated. A LR+ is the ratio between the probability of a positive test result if the impairment is present versus the probability of a positive test result if the impairment is absent (True positive rate/ False positive rate) (Davidson, 2002, Grimes and Schulz, 2005). Vice versa a LR- is the ratio of the True negative rate/ False negative rate (Davidson, 2002, Grimes and Schulz, 2005). In general, tests with LR values close to "1" provide little additional information. A LR+ between 3 and 10 is regarded "moderately positive" and above 10 "very positive" (Sackett, 2000). A LR- between 0.3 and 0.1 is regarded "moderately negative" and below 0.1 "extremely negative" (Sackett, 2000).

In a subgroup analysis of co-variances (ANCOVA), differences in outcome variables between individuals with INP and WAD were examined while adjusting for age, NDI-score, and the pre-test pain intensity status as covariates.

\section{Results}

Data from 76 subjects ( 38 NP and 38 gender-and age matched asymptomatic control subjects) was collected. The mean age (standard deviation) of the NP was 34.95 (12.53) years, compared to 35.13 (13.18) years in the control group. Further details are given in Table 1 for all cases and controls, and Table 2 for the subgroups of WAD and INP cases.

Individuals with NP used more time approximately 4.5 seconds more for $Z Z$ ( $t=1.70, p=0.09)$ and 5.5 seconds more for F8 $(t=2.22, p=0.03$, Table 1$)$. The NP group had approximately 3 to 4 more errors for $\mathrm{ZZ}(\mathrm{t}=3.9, \mathrm{p}<0.01)$, and 13 more errors for F8 $(t=7.2, p<0.01$, Table 1$)$ compared to controls. Sensitivity, specificity, LR+ and LR-values for optimal cut offs were higher for number of errors than for time.

Optimal cutoffs of 10 errors for F8 and 9 errors for ZZ, provided moderately positive LR+ with 3.78 and 3.00 respectively, and moderately negative LR- 0.14 for F8, but above threshold with 0.38 for ZZ. 
Likelihood values for time variables achieved a maximum LR+ of 1.54 for F8 and 1.38 for ZZ and LR-

Using different cut-offs did affect number of errors with a LR+ of 11 for a 16 errors cut-off during F8 tracing, making it "very positive" while a cut-off 8 errors during F8 tracing led to a LR- of 0.08 , which is regarded as "extremely negative" (Sackett, 2000). Further values are presented in Table 3. subjects performed the ZZ pattern significantly faster, and generated on average 5.8 more errors than INP subjects, a non-significant trend ( $p=0.11$, Table 2$)$, during F8.

Table 1: Demographics and between group differences (mean and standard deviation) for time taken and number of errors for the Zig Zag (ZZ) and Figure of eight (F8) pattern tracing.

\begin{tabular}{|c|c|c|c|c|}
\hline Va & able & Controls $(n=38)$ & $\begin{array}{l}\text { Neck pain subjects } \\
(n=38)\end{array}$ & p-value \\
\hline $\mathrm{Ge}$ & $\operatorname{der}(f / m)$ & $21 / 17$ & $21 / 17$ & 1 \\
\hline $\mathrm{Ag}$ & (years) & 35.13 (13.18) & 34.95 (12.53) & 0.95 \\
\hline ND & & $0.89(1.37)$ & $22.36(10.06)$ & $<0.001$ \\
\hline & sf / 13 & $12.89(0.51)$ & $10.66(2.56)$ & $<0.001$ \\
\hline & ation in months & NA & $67(76))$ & NA \\
\hline Pai & VAS/100 mm & $0(0)$ & $25.61(21.54)$ & $<0.001$ \\
\hline F8 & Time (sec) & $25.4(10.1)$ & 30.9 (11.6) & 0.03 \\
\hline & Number of errors & $7.4(4.5)$ & $20.6(10.3)$ & $<0.001$ \\
\hline $\mathrm{ZZ}$ & Time(sec) & $23.3(11)$ & $27.8(12.5)$ & 0.09 \\
\hline & Number of errors & $7.5(3.1)$ & $11.2(4.7)$ & $<0.001$ \\
\hline
\end{tabular}

Table 2: Demographics (mean and standard deviation) and between neck pain group (whiplash and pattern tracing.

\begin{tabular}{|l|l|l|l|}
\hline \multicolumn{1}{|c|}{ Group } & $\begin{array}{l}\text { Idiopathic neck pain } \\
(\mathbf{n = 2 5})\end{array}$ & $\begin{array}{l}\text { Whiplash associated disorders } \\
(\mathrm{n}=\mathbf{1 3})\end{array}$ & $\begin{array}{l}\mathrm{p} \text { - } \\
\text { value }\end{array}$ \\
\hline Variable & $14 / 11$ & $7 / 6$ & 1 \\
\hline Age (years) & $\mathbf{3 1 . 7 2 ( 1 2 . 0 3 )}$ & $\mathbf{4 1 . 1 5 ( 1 1 . 4 6 )}$ & $\mathbf{0 . 0 3}$ \\
\hline
\end{tabular}




\begin{tabular}{|c|c|c|c|c|}
\hline \multicolumn{2}{|c|}{ NDI \% } & $20.88(10.08)$ & $25.24(9.78)$ & 0.21 \\
\hline \multicolumn{2}{|c|}{ DHIsf/13 } & $10.48(2.85)$ & $11(1.96)$ & 0.51 \\
\hline \multicolumn{2}{|c|}{ Duration in months } & $63(80)$ & $75(70)$ & 0.64 \\
\hline \multicolumn{2}{|c|}{ Pain on $100 \mathrm{~mm}$ VAS } & $20.12(21.56)$ & $36.15(17.81)$ & 0.02 \\
\hline \multirow[t]{2}{*}{ F8 } & Time (sec) & $32.05(12.1)$ & $28.67(12.6)$ & 0.45 \\
\hline & $\begin{array}{l}\text { Number of } \\
\text { errors }\end{array}$ & $18.6(9.4)$ & $24.4(9.8)$ & 0.11 \\
\hline \multirow[t]{2}{*}{$\mathrm{ZZ}$} & Time (sec) & 31 (12.7) & $21.8(9.8)$ & 0.02 \\
\hline & $\begin{array}{l}\text { Number of } \\
\text { errors }\end{array}$ & $11(5.2)$ & $11(5.4)$ & 0.99 \\
\hline
\end{tabular}

$\mathrm{NDI}=$ Neck disability index; DHIsf= Dizziness handicap inventory short form; VAS = Visual analogue

scale; F8 and ZZ outcome values were adjusted for pre-test pain, age and NDI.

Table 3: Sensitivity, specificity, LR+ and LR- for number of errors and time variables

\begin{tabular}{|c|c|c|c|c|c|}
\hline Parameter & Cut-off & Sensitivity & Specificity & LR+ & LR- \\
\hline \multirow[t]{4}{*}{ F8 time } & $20 \mathrm{sec}$ & $\begin{array}{l}0.89 \\
(0.75,0.97)\end{array}$ & $\begin{array}{l}0.34 \\
(0.20,0.51)\end{array}$ & $\begin{array}{l}1.36 \\
(1.06,1.75)\end{array}$ & $\begin{array}{l}0.31 \\
(0.11,0.86)\end{array}$ \\
\hline & $24 \mathrm{sec}$ & $\begin{array}{l}0.68 \\
(0.51,0.82)\end{array}$ & $\begin{array}{l}0.47 \\
(0.31,0.64)\end{array}$ & $\begin{array}{l}1.30 \\
(0.90,1.88)\end{array}$ & $\begin{array}{l}0.67 \\
(0.37,1.19)\end{array}$ \\
\hline & $28 \mathrm{sec}$ & $\begin{array}{l}0.53(0.36, \\
0.69)\end{array}$ & $\begin{array}{l}0.66(0.49, \\
0.80)\end{array}$ & $\begin{array}{l}1.54(0.90, \\
2.62)\end{array}$ & $\begin{array}{l}0.72(0.48, \\
1.08)\end{array}$ \\
\hline & 32 secs & $\begin{array}{l}0.37(0.22, \\
0.54)\end{array}$ & $\begin{array}{l}0.76(0.60, \\
0.89)\end{array}$ & $\begin{array}{l}1.56(0.77, \\
3.15)\end{array}$ & $\begin{array}{l}0.83(0.61, \\
1.12)\end{array}$ \\
\hline \multirow[t]{5}{*}{$\begin{array}{l}\text { F8 number of } \\
\text { errors }\end{array}$} & 8 Errors & $\begin{array}{l}0.95(0.82, \\
0.99)\end{array}$ & $\begin{array}{l}0.63(0.46, \\
0.78)\end{array}$ & $\begin{array}{l}2.57(1.68, \\
3.93)\end{array}$ & $\begin{array}{l}0.08(0.02, \\
0.33)\end{array}$ \\
\hline & 10 Errors & $\begin{array}{l}0.87(0.72, \\
0.96)\end{array}$ & $\begin{array}{l}0.76(0.60, \\
0.89)\end{array}$ & $\begin{array}{l}3.67(2.04, \\
6.58)\end{array}$ & $\begin{array}{l}0.17(0.07, \\
0.40)\end{array}$ \\
\hline & 12 Errors & $\begin{array}{l}0.76(0.60, \\
0.89)\end{array}$ & $\begin{array}{l}0.79(0.63, \\
0.90)\end{array}$ & $\begin{array}{l}3.63(1.91, \\
6.88)\end{array}$ & $\begin{array}{l}0.30(0.17, \\
0.54)\end{array}$ \\
\hline & 14 Errors & $\begin{array}{l}0.63(0.46, \\
0.78)\end{array}$ & $\begin{array}{l}0.89(0.75, \\
0.97)\end{array}$ & $\begin{array}{l}6.00(2.30, \\
15.64)\end{array}$ & $\begin{array}{l}0.41(0.27, \\
0.63)\end{array}$ \\
\hline & 16 Errors & $\begin{array}{l}0.58(0.41, \\
0.74)\end{array}$ & $\begin{array}{l}0.95(0.82, \\
0.99)\end{array}$ & $\begin{array}{l}11.00(2.78, \\
43.55)\end{array}$ & $\begin{array}{l}0.44(0.30, \\
0.65)\end{array}$ \\
\hline \multirow[t]{5}{*}{ ZZ time } & $16 \mathrm{sec}$ & $\begin{array}{l}0.87(0.72, \\
0.96)\end{array}$ & $\begin{array}{l}0.34(0.20, \\
0.51)\end{array}$ & $\begin{array}{l}1.32(1.02, \\
1.71)\end{array}$ & $\begin{array}{l}0.38(0.15, \\
0.97)\end{array}$ \\
\hline & $20 \mathrm{sec}$ & $\begin{array}{l}0.71(0.54, \\
0.85)\end{array}$ & $\begin{array}{l}0.45(0.29 \\
0.62)\end{array}$ & $\begin{array}{l}1.29(0.91, \\
1.83)\end{array}$ & $\begin{array}{l}0.65(0.35, \\
1.19)\end{array}$ \\
\hline & $24 \mathrm{sec}$ & $\begin{array}{l}0.50(0.33, \\
0.67)\end{array}$ & $\begin{array}{l}0.61(0.43, \\
0.76)\end{array}$ & $\begin{array}{l}1.27(0.76, \\
2.10) \\
\end{array}$ & $\begin{array}{l}0.83(0.55, \\
1.24)\end{array}$ \\
\hline & $28 \mathrm{sec}$ & $\begin{array}{l}0.47(0.31, \\
0.64)\end{array}$ & $\begin{array}{l}0.66(0.49, \\
0.80)\end{array}$ & $\begin{array}{l}1.38(0.80, \\
2.41)\end{array}$ & $\begin{array}{l}0.80(0.55, \\
1.17)\end{array}$ \\
\hline & $32 \mathrm{sec}$ & $\begin{array}{l}0.26(0.13, \\
0.43)\end{array}$ & $\begin{array}{l}0.71(0.54, \\
0.85)\end{array}$ & $\begin{array}{l}0.91(0.44, \\
1.88)\end{array}$ & $\begin{array}{l}1.04 \text { (0.79, } \\
1.37)\end{array}$ \\
\hline $\begin{array}{l}\text { ZZ number of } \\
\text { errors }\end{array}$ & 5 errors & $\begin{array}{l}0.92(0.79, \\
0.98)\end{array}$ & $\begin{array}{l}0.21(0.10, \\
0.37)\end{array}$ & $\begin{array}{l}1.17(0.97, \\
1.41)\end{array}$ & $\begin{array}{l}0.38 \text { (0.11, } \\
1.31)\end{array}$ \\
\hline
\end{tabular}




\begin{tabular}{|l|l|l|l|l|l|}
\hline \multirow{2}{*}{7 errors } & $0.79(0.63$, & $0.47(0.31$, & $1.50(1.06$, & $0.44(0.22$, \\
& & $0.90)$ & $0.64)$ & $2.11)$ & $0.90)$ \\
\cline { 2 - 6 } & $\mathbf{9}$ errors & $\mathbf{0 . 7 1 ( 0 . 5 4 ,}$ & $\mathbf{0 . 7 6 ( 0 . 6 0 ,}$ & $\mathbf{3 . 0 0 ( 1 . 6 4 ,}$ & $\mathbf{0 . 3 8}(\mathbf{0 . 2 2}$, \\
& $\mathbf{0 . 8 5 )}$ & $\mathbf{0 . 8 9})$ & $\mathbf{5 . 5 0 )}$ & $\mathbf{0 . 6 4 )}$ \\
\cline { 2 - 6 } & 11 errors & $0.50(0.33$, & $0.82(0.66$, & $2.71(1.29$, & $0.61(0.43$, \\
& $0.67)$ & $0.92)$ & $5.69)$ & $0.87)$ \\
\cline { 2 - 6 } & 13 errors & $0.37(0.22$, & $0.92(0.79$, & $4.67(1.46$, & $0.69(0.53$, \\
& $0.54)$ & $0.98)$ & $14.93)$ & $0.89)$ \\
\hline
\end{tabular}

Sens= Sensitivity; Spec= Specificity; LR+= positive Likelihood ratio; LR- = negative Likelihood ratio; 95\% Confidence intervals in brackets, optimal cut offs in bold

\section{Discussion}

The current study supports the validity and clinical utility of this simple and inexpensive measure to assess CMS in individuals with NP and provides guidance as to potential measures that could be used clinically to determine abnormal CMS. We showed that individuals with NP differ to age- and gender matched controls in CMS with significantly more errors while tracing both a F8 and ZZ pattern. Although individuals with NP needed more time for tracing both patterns, significance was only achieved for the F8 tracing (Table 3). Number of errors for optimal cut off values overall showed moderate likelihoods, meaning a test result with more than nine errors for ZZ OR 10 errors for F8 tracing, respectively strengthens the likelihood of the CMS performance differing from asymptomatic people. Encouragingly, our LR values based on a simple clinical measure are similar to those calculated from values reported for cervical movement accuracy during left and right rotation as detected by more sophisticated technology (LR+: 2-3.57, LR-: 0.3 -0.58) (Sarig Bahat et al., 2015a).

High likelihood values were not expected, as sensorimotor dysfunction is not a generic feature, and in individuals with NP, demonstrates the importance of establishing values that provide the best specificity i.e. ability to distinguish from a normal performance. Our findings provide some guidance for what might be considered a "normal" performance with nine or less errors for ZZ and ten or less for F8 pattern tracing. Further distinction may apply if the test is completed within 28 seconds although this has less clinical significance (Table 3). 
The results also support the use of real time error counting, making the assessment feasible in the clinical setting. This is in agreement with a study indicating perfect and high reliability for both time and number of errors to trace both patterns (Werner et al., 2018). The current study corroborates these findings using age- and gender-matched neck pain and control groups, given both variables are known to affect CMS (Kristjansson et al., 2016, Oddsdottir et al. , 2013, Sarig Bahat H, 2016).

We regard the increased number of errors while performing $\mathrm{ZZ}$ and F8 patterns in the neck pain group as indicative of impaired movement accuracy. According to the accuracy speed trade-off, less error is usually associated with longer time to complete a movement task; however, this was not the case in the participants with neck pain, which suggests poorer overall accuracy (Sandlund et al. , 2008). Woodhouse et al. have shown similar findings with WAD subjects demonstrating more irregular head movements while tracking the F8 pattern with a slow predetermined speed compared to healthy controls and INP, but not with a given faster speed (Woodhouse et al., 2010b). Further, this finding is in line with other studies using more sophisticated equipment where increased "jerkiness" or greater deviation from a moving target position are reported to reflect impaired smoothness in movement (Kristjansson et al., 2016, Kristjansson and Oddsdottir, 2010, Michiels et al. , 2014, Oddsdottir and Kristjansson, 2012, Sarig Bahat et al., 2015a, Woodhouse et al., 2010b).

The current study also compared results from individuals with idiopathic neck pain and those with whiplash. Those who have had trauma and or dizziness are thought to be more likely to have greater proprioceptive deficits (Woodhouse et al., 2010b). However, we identified the only significant difference between groups to individuals with INP needing more time to trace the ZZ pattern (Table 2). It appears that the WAD patients demonstrated superior accuracy-speed trade off during ZZ as they moved faster without increased number of errors. In completing F8 tracing, WAD patients generated approximately six errors more than INP, but this was not significantly different $(p=0.11)$ (Table 2) (Sandlund et al., 2008). The rationale for different findings for ZZ compared to F8 is unclear but we 
speculate this relates to the complexity of the tracing task where F8 may require multi-planar motion and non-linear trajectories while ZZ requires bi-planar motions (Michiels et al., 2013). Alternatively, it could reflect a change in strategy in WAD with a more difficult task. Similar changes in strategy have been seen in other studies on sensorimotor control comparing WAD and INP (Field et al. , 2008, Treleaven and Takasaki, 2015). For example, in a more difficult balance task, WAD subjects tended to stiffen with a decrease in sway compared to both INP and to an easier task where they had increased sway compared to INP (Field et al., 2008). Nevertheless, these findings should be interpreted with caution as subject numbers in this group were low and overall levels of pain and dizziness were mild. Further, idiopathic and whiplash patients groups were not aged matched, with whiplash patients approximately ten years older (Table 2). However, values of outcome variables were statistically adjusted for these differences. Further research should be conducted in larger sample sizes of neck pain populations, and including individuals with higher levels of pain and dizziness. Limitations This study has some limitations that should be considered in interpreting the results. First, the sample size, especially for the WAD group is small and may affect the subgroup analysis. Second, we used a web-cam to record videos and assessed them at a later date. Furthermore, at both sites we used mean values, rated by two raters, for outcome variables, which would not be feasible in daily practice. However, as the reliability of raters is previously shown to be high, ratings by a single rater are sufficiently reliable (Werner et al., 2018). Potential rater bias had been minimised by keeping raters blind to each other and by blinding them to subjects' clinical details. Future studies should explore test -retest reliability for subjects' performance, as individual variability may occur, so as learning or fatigue (Woodhouse et al. , 2010a). In line with this responsiveness of the measure, post- intervention and performance comparison to more sophisticated measures will also be important future research directions. Automated analysis of

237 videos for time, number of errors and other variables relating to error might also be relevant (Röijezon et al. , 2017). 
The simple clinical measure to count number of errors and the time taken to trace a F8 or ZZ pattern

241 with a laser pointer affixed to the patient's head appears suitable in assessing movement sense

242 impairment in neck pain patients. Our findings indicate that examining time alone is of insufficient

243 clinical merit with number of errors appearing superior. Neck pain patients in general perform worse

than age-and gender matched healthy subjects for both patterns. Some differences were seen in

those with WAD but this requires further exploration. Clinical interpretation should consider more

than nine errors for $\mathrm{ZZ}$ and ten errors for $\mathrm{F} 8$ to increase the probability of movement sense

prioritise testing the ZZ pattern as this has superior reliability and clinical feasibility, and remained

Funding:

This research did not receive any specific grant from funding agencies in the public, commercial, or not-for-profit sectors.

Akobeng AK. Understanding diagnostic tests 3: receiver operating characteristic curves. Acta Paediatrica. 2007;96:644-7.

Davidson M. The interpretation of diagnostic tests: a primer for physiotherapists. Australian Journal of Physiotherapy. 2002;48:227-32.

Field S, Treleaven J, Jull G. Standing balance: a comparison between idiopathic and whiplash-induced neck pain. Man Ther. 2008;13:183-91.

Grimes DA, Schulz KF. Refining clinical diagnosis with likelihood ratios. The Lancet. 2005;365:1500-5. Jacobson GP, Newman CW. The development of the Dizziness Handicap Inventory. Archives of otolaryngology--head \& neck surgery. 1990;116:424-7.

Jensen MP, Karoly P, Braver S. The measurement of clinical pain intensity: a comparison of six methods. Pain. 1986;27:117-26.

Jull G, Sterling M, Falla D, Trelevaen J, O'Leary S. Whiplash, Headache, and Neck pain: Researchbased directions for physical therapies. Edinburgh: Churchill Livingstone Elsevier; 2008.

Kristjansson E, Björnsdottir SV, Oddsdottir GL. The long-term course of deficient cervical kinaesthesia following a whiplash injury has a tendency to seek a physiological homeostasis. A prospective study. Manual Therapy. 2016;22:196-201. 
Kristjansson E, Oddsdottir GL. "The Fly": a new clinical assessment and treatment method for deficits of movement control in the cervical spine: reliability and validity. Spine (Phila Pa 1976). 2010;35:E1298-305.

Kristjansson E, Treleaven J. Sensorimotor function and dizziness in neck pain: implications for assessment and management. The Journal of orthopaedic and sports physical therapy. 2009;39:364-77.

Kulkarni V, Chandy MJ, Babu KS. Quantitative study of muscle spindles in suboccipital muscles of human foetuses. Neurology India. 2001;49:355-9.

Liu JX, Thornell LE, Pedrosa-Domellof F. Muscle spindles in the deep muscles of the human neck: a morphological and immunocytochemical study. J Histochem Cytochem. 2003;51:175-86.

MacDermid JC, Walton DM, Avery S, Blanchard A, Etruw E, McAlpine C, et al. Measurement properties of the neck disability index: a systematic review. The Journal of orthopaedic and sports physical therapy. 2009;39:400-17.

McLain RF. Mechanoreceptor endings in human cervical facet joints. Spine (Phila Pa 1976). 1994;19:495-501.

Meisingset I, Stensdotter A-K, Woodhouse A, Vasseljen O. Neck motion, motor control, pain and disability: A longitudinal study of associations in neck pain patients in physiotherapy treatment. Manual Therapy. 2015.

Michiels S, De Hertogh W, Truijen S, November D, Wuyts F, Van de Heyning P. The assessment of cervical sensory motor control: a systematic review focusing on measuring methods and their clinimetric characteristics. Gait \& posture. 2013;38:1-7.

Michiels S, Hallemans A, Van de Heyning P, Truijen S, Stassijns G, Wuyts F, et al. Measurement of cervical sensorimotor control: the reliability of a continuous linear movement test. Man Ther. 2014;19:399-404.

Oddsdottir GL, Kristjansson E. Two different courses of impaired cervical kinaesthesia following a whiplash injury. A one-year prospective study. Man Ther. 2012;17:60-5.

Oddsdottir GL, Kristjansson E, Gislason MK. Database of movement control in the cervical spine. Reference normal of 182 asymptomatic persons. Man Ther. 2013;18:206-10.

Peña EA, Slate EH. Global Validation of Linear Model Assumptions. Journal of the American Statistical Association. 2006;101:341-54.

Pereira MJ, Beaudin C, Grewal G, Wong V, Treleaven J. Cervical Movement Sense: Normative Data for a Clinical Tool. Australian physiotherapy association conference: "New moves" Data provided by the first author as presented at the conference. Melbourne: Australian physiotherapy association; 2013.

R-Development-Core-Team. R: A Language and Environment for Statistical Computing. Vienna, Austria: R Foundation for Statistical Computing; 2008.

Richmond FJ, Bakker DA. Anatomical organization and sensory receptor content of soft tissues surrounding upper cervical vertebrae in the cat. Journal of neurophysiology. 1982;48:49-61.

Roijezon U, Clark NC, Treleaven J. Proprioception in musculoskeletal rehabilitation. Part 1: Basic science and principles of assessment and clinical interventions. Man Ther. 2015;20:368-77.

Röijezon U, Faleij R, Karvelis P, Georgoulas G, Nikolakopoulos G. A new clinical test for sensorimotor function of the hand - development and preliminary validation. BMC Musculoskeletal Disorders. 2017;18:407.

Sackett DL. Evidence-based Medicine: How to Practice and Teach EBM. second ed. Edinburgh: Churchill Livingstone; 2000.

Sandlund J, Roijezon U, Bjorklund M, Djupsjobacka M. Acuity of goal-directed arm movements to visible targets in chronic neck pain. J Rehabil Med. 2008;40:366-74.

Sarig Bahat H, Chen X, Reznik D, Kodesh E, Treleaven J. Interactive cervical motion kinematics: sensitivity, specificity and clinically significant values for identifying kinematic impairments in patients with chronic neck pain. Man Ther. 2015a;20:295-302.

Sarig Bahat H IM, Quek J, Treleaven J. Cervical Kinematics of Fast Neck Motion across Age. J Nov Physiother. 2016;6:306. 
Sarig Bahat $\mathrm{H}$, Takasaki $\mathrm{H}$, Chen X, Bet-Or Y, Treleaven J. Cervical kinematic training with and without interactive VR training for chronic neck pain - a randomized clinical trial. Man Ther. 2015b;20:68-78.

Sing T, Sander O, Beerenwinkel N, Lengauer T. Visualising the performance of scoring classifiers. $R$ Foundation for Statistical Computing; 2015.

Stevenson M. epiR: Tools for the analysis of epidemiological data. R Foundation for Statistical Computing; 2018.

Streiner DL, Norman GR. Health measurement scales. 4th ed. Oxford, UK: Oxford University Press; 2008.

Tesio L, Alpini D, Cesarani A, Perucca L. Short form of the Dizziness Handicap Inventory: construction and validation through Rasch analysis. American journal of physical medicine \& rehabilitation. 1999;78:233-41.

Treleaven J. Dizziness, unsteadiness, visual disturbances, and postural control: implications for the transition to chronic symptoms after a whiplash trauma. Spine (Phila Pa 1976). 2011;36:S211-7.

Treleaven J, Peterson G, Ludvigsson ML, Kammerlind A-S, Peolsson A. Balance, dizziness and proprioception in patients with chronic whiplash associated disorders complaining of dizziness: A prospective randomized study comparing three exercise programs. Manual Therapy. 2016;22:122-30.

Treleaven J, Takasaki H. High variability of the subjective visual vertical test of vertical perception, in some people with neck pain - Should this be a standard measure of cervical proprioception? Man Ther. 2015;20:183-8.

Vernon H. The Neck Disability Index: state-of-the-art, 1991-2008. J Manipulative Physiol Ther. 2008;31:491-502.

Vernon H, Mior S. The Neck Disability Index: a study of reliability and validity. J Manipulative Physiol Ther. 1991;14:409-15.

Werner IM, Ernst MJ, Treleaven J, Crawford RJ. Intra and interrater reliability and clinical feasibility of a simple measure of cervical movement sense in patients with neck pain. BMC Musculoskeletal Disorders. 2018;19:358.

Woodhouse A, Liljeback P, Vasseljen $O$. Reduced head steadiness in whiplash compared with nontraumatic neck pain. J Rehabil Med. 2010a;42:35-41.

Woodhouse A, Stavdahl O, Vasseljen O. Irregular head movement patterns in whiplash patients during a trajectory task. Experimental brain research. 2010b;201:261-70. 